LINGUA, Vol. 12, No. 1, Maret 2015

p ISSN: 1979 9411; e ISSN: 2442 238X; Web: lingua.pusatbahasa.or.id Pusat Kajian Bahasa dan Budaya, Surakarta, Indonesia

Mahyudi, Johan. 2015. Jejak Wordsworth, Coleridge, dan Shelly pada Sejumlah Sajak Chairil Anwar yang Dilengkapi Nama Wanita. Lingua, 12(1): 71 84.

\title{
JEJAK WORDSWORTH, COLERIDGE, DAN SHELLEY PADA SEJUMLAH SAJAK CHAIRIL ANWAR YANG DILENGKAPI NAMA WANITA
}

\author{
Johan Mahyudi \\ Universitas Mataram \\ Email: johanmahyudi@gmail.com
}

\begin{abstract}
Almost all critiqus admit the quality of Chairicl Anwar's verses as of impressed. On a poem he exlicitly dedicated to a certain woman he loved, Chairil Anwar impressively exposed his romantic articulation in the poet. Results of inquiry upon three poems of Chairil Anwar indicated the root of romantic initiators that derived from romantic expressions of Wordsworth, Coleridge, and Shelley. Innovations on the romantic expression the poets delivered for critiques, romantism has been a new mainstream in the literary critique. This article presents how Chairil Anwar strongly expresses romantic articulations in his three poems Cerita Buat Dien Tamaela (A Story for Dien Tamalea), Sajak Putih (A White Verse), Hampa (Empty), and Senja di Pelabuhan Kecil (Twilight in a Small Port). The findings evidently indicated that Chairil Anawar adapted Wordsworth romantism version, and Senja di Pelabuhan Kecil was a poet Chairil Anwar ideally devoted romantism spirit.
\end{abstract}

Key-words: romantism poet, verse, Chairil Anwar.

Chairil Anwar pada beberapa sajaknya, secara eksplisit menulis nama wanita, yang menjelaskan untuk siapa ia sengaja menulisnya. Saat ini, hampir semua orang yang mengenal penyair ini, segera akan memberikan klaim positif tentang kekuatan kata-kata romantik yang telah diciptakannya. Sekilas nampaknya hal itu merupakan sebuah keberuntungan yang jarang bisa diterima kecuali hanya oleh penyair yang dianggap mewakili bangsanya. Bahkan banyak orang dan kalangan akademisi seperti menutup mata atas tuduhan plagiasi yang melanda Chairil. Karena kepopuleran namanya,Chairil Anwar bahkan menjadi semacam acuan pembuatan nama anak-anak Indonesia yang lahir kemudian. Lalu sekali lagi, saat Chairil Anwar menulis sajak-sajak yang secara jelas tidak mewakili spirit bangsanya, melainkan hanya sebagai wujud ekpresi kerinduannya pada seorang wanita, dengan menulis nama-nama mereka di awal sajak, atau sebagai bagian dari judul, romantismeala Chairil Anwar tetap dikagumi. Sulit menemukan ada kritikus puisi yang akan menganggap salah satu karya Chairil Anwar sebagai sajak murahan.

Bagaimana Chairil Anwar bisa selamat dari berbagai uji publik tersebut? Bahkan tetap bertengger pada posisi tertinggi pada tangga penyair Indonesia terpopuler? Ada banyak argumen yang bisa diajukan untuk menjawabnya. Tulisan ini akan menjelaskan salah satu alasannya. Pada sajak yang secara eksplisit diperuntukkan bagi wanita tertentu,Chairil Anwar tetap bisa mempertahankan kualitasromantiskanya. Penelusuran atas tiga sajak Chairil 
menunjukkan bahwa romantika yang diterapkan nampaknya berakar dari pemikiran para penggagas romantisme, seperti Wordsworth, Coleridge, dan Shelley.

Pemikiran romantik tumbuh di Eropa menjelang akhir abad ke-18 sebagai reaksi atas perbedaan pandangan politik. Dengan berbagai inovasi yang dilakukan oleh para pencetusnya, romantisme kemudian menjadi sebuah pendekatan yang sepenuhnya menunjukkan model kritik baru. Meskipun pada perkembangannya, kritik romantik merupakan eksperimen sejumlah pencetus aliran ini atas usaha untuk menjelaskan karya mereka sendiri, pada akhirnya ada pola yang dapat ditelusuri yang memberi harapan lebih terang mengenai sebuah pendekatan yang menjanjikan untuk bisa melihat keindahan puisi.

Sajak-sajak Chairil yang dianggap meneruskan spirit penggagas aliran romantik itu anatara lain berjudul Cerita Buat Dien Tamaela, Sajak Putih, Hampa,dan Senja di Pelabuhan Kecil.Dalam tulisan ini, secara berurutan akan dibahas pengaruh ketiga penggagas romantisme di atas, dengan cara mengulas pemikiran mereka, satu per satu, lalu diikuti dengan pembahasan pengaruhnya pada puisi Chairil. Pada bagian akhir, diharapkan ada gembaran tentang tokoh mana yang paling mempengaruhi Chairil, serta puisi mana yang paling romantis. Dengan sendirinya, pengetahuan atas informasi terakhir itu akan mengarahkan pada informasi mengenai siapa yang paling disayangi oleh Chairil Anwar.

\section{JEJAK WORDSWORTH PADA PUISI SENJA DI PELABUHAN KECIL}

William Wordsworth, lahir di Cockermouth, Kerajaan Inggris, 7 April 1770meninggal di Cumberland, Inggris, 23 April 1850 pada umur 80 tahun. Dia adalah salah salah seorang penyair Inggris terkemuka, turut mengagas dan menyuburkan romantisme. Karya terkenalnya ialah Lyrical Ballads.Golban, (2012) menjelaskan bawa subjek puisi Wordsworth merupakan suatu usaha kompleks, terdiri dari peristiwa dan situasi dari kehidupan umum, berbagai hal biasa, pola hidup pedusunan nan sederhana, penderitaan karena mementingkan hasrat hati, perasaan dasar kita, tatakrama dari hidup pedesaan, jabatan dan kedudukan di pedesaan, penderitaan karena hasrat orang, hukum alam yang permanen dan indah. Wordsworth kerap membicarakan tentang pemilihan bahasa yang benar-benar digunakan oleh orang harusnya lebih sederhana, tegas, filosofis, mengandung teladan yang adakalanya dibisikkan oleh karena adanya penderitaan hasrat. Puisi yang terbaik dapat ditemukan dalam bahasa prosa, terutama jika prosanya ditulis dengan sungguh-sungguh baik. Tujuan puisi, menurut Wordsworth, ialah membuat pembaca memahami apa yang ditulis dalam puisi. Tetapi pemahaman itu haruslah dapat mencerahkan dalam beragam tingkatan, karena kasih sayang yang ada dalam diri pembaca akan memperkuat dan membersihkannya dari penderitaan akan hasrat. Itulah sebabnya saat membicarakan dasar penciptaan puisi, Wordsworth menjelaskan bahwa puisi adalah luapan perasaan yang muncul secara spontan dari perasaan sesaat yang kuat.

Dari pemikiran Wordsworth di atas, diperoleh sejumlah parameter untuk menentukan kualitas sebuah puisi, terutama dari aspek romantiknya. Parameter itu antara lain:

1. Peristiwa dan situasi yang diungkapkan berasal dari kehidupan umum, biasa, dan sederhana;

2. Mengungkapkan hukum alam yang permanen dan indah;

3. Mengungkapkan penderitaan karena mementingkan hasrat sendiri; 
LINGUA, Vol. 12, No. 1, Maret 2015

p ISSN: 1979 9411; e ISSN: 2442 238X; Web: lingua.pusatbahasa.or.id Pusat Kajian Bahasa dan Budaya, Surakarta, Indonesia

Mahyudi, Johan. 2015. Jejak Wordsworth, Coleridge, dan Shelly pada Sejumlah Sajak Chairil Anwar yang Dilengkapi Nama Wanita. Lingua, 12(1): 71 84.

4. Mengungkapkan penderitaan karena mementingkan hasrat orang;

5. Mengungkapkan perasaan dasar manusia;

6. Mengandung teladan yang adakalanya dibisikkan oleh penderitaan;

7. Membuat pembaca memahami dan merasa tercerahkan dalam beragam tingkatan hingga membentuk ribuan kombinasi pikiran yang tidak dapat dikekang;

8. Mengandung bahasa filosofis yang mendalam;

Puisi Senja di Pelabuhan Kecil ditulis oleh Chairil Anwar pada tahun 1946 diperuntukkan buat Sri Ajati. Informasi tentang sosok ini sangat sedikit. Dari penuturan Evawani, putri Chairil Anwal (Kompas, 2013) diketahui bahwa Sri Ajati ialah sosok wanita yang pernah dicintai oleh ayahnya itu saat Chairil Anwar bekerja sebagai penyiar radio Jepang. Cinta itu beritanya tidak pernah berani dinyatakan, kecuali dalam sajak, seperti yang dapat dibaca berikut ini.

\title{
SENJA DI PELABUHAN KECIL
}

\author{
buat Sri Ajati \\ Ini kali tidak ada yang mencari cinta \\ di antara gudang, rumah tua, pada cerita \\ tiang serta temali. Kapal, perahu tiada berlaut \\ menghembus diri dalam mempercaya mau berpaut. \\ Gerimis mempercepat kelam. Ada juga kelepak elang \\ menyinggung muram, desir hari lari berenang \\ menemu bujuk pangkal akanan. Tidak bergerak \\ dan kini tanah dan air tidur hilang ombak. \\ Tiada lagi. Aku sendiri. Berjalan \\ menyisir semenanjung, masih pengap harap \\ sekali tiba di ujung dan sekalian selamat jalan \\ dari pantai ke empat, sedu penghabisan bisa terdekap.
}

Kualitas puisi di atas jika ditinjau dengan menggunkan parameter Wordsworth, yang pertama kali harus dilakukan ialah menemukan pengungkapan peristiwa dan situasi yang berasal dari kehidupan umum, biasa, dan sederhana. Dalam puisi Senja di Pelabuhan Kecil, pengungkapan semacam itu, sangat jelas mulai dari judul hingga seluruh bagian bait pertamanya. Senja di Pelabuhan Kecil. Sebuah peristiwa umum, biasa, dan sederhana, yang terjadi di sebuah pelabuhan yang kecil. Situasi yang ditemukan di sebuah pelabuhan kecil saat senja tiba ialah suasana sepi yang membuat semua yang oleh keramaian mungkin tidak akan diperhatikan, lalu karena sepi, akhirnya terlihat jelas gudang, rumah tua, tali, kapal, perahu, dan laut. Penggambaran itu terlihat pada kutipan berikut /Ini kali tidak ada yang mencari 
LINGUA, Vol. 12, No. 1, Maret 2015

p ISSN: 1979 9411; e ISSN: 2442 238X; Web: lingua.pusatbahasa.or.id

Pusat Kajian Bahasa dan Budaya, Surakarta, Indonesia

Mahyudi, Johan. 2015. Jejak Wordsworth, Coleridge, dan Shelly pada Sejumlah Sajak Chairil Anwar yang Dilengkapi Nama Wanita. Lingua, 12(1): 71 84.

cinta/di antara gudang, rumah tua, pada ceritaltiang serta temali. Kapal, perahu tiada berlaut/ menghembus diri dalam mempercaya mau berpaut/.

Parameter kedua ialah adanya pengungkapan hukum alam yang permanen dan indah. Pada puisi Senja di Pelabuhan Kecil hukum alam dapat kita temukan pada awal bait kedua / Gerimis mempercepat kelam/... Tentu saja, gerimis yang muncul karena adanya mendung, akan membuat suasana sore yang sudah berkurang terpaan sinar mataharinya menjadi bertambah gelap. Apalagi jika gerimisnya disebabkan oleh mendung tebal menjelang hujan, suasana sore, tidak hanya di pelabuhan, tetapi tempat lain juga akan menjadi lebih gelap sehingga malam hari seperti datang lebih cepat. Hukum alam yang dikemukakan dalam puisi itu juga disusun dalam larik yang indah dan memebri kesan yang indah. Katamempercepat digunakan oleh Chairil untuk menyambung gerimis dan kelam. Efek kata mempercepat selalu lebih kuat dibandingkan dengan kata membuat, menjadikan, menuju, atau menyusul. Tidak ada pernyataan sebab-akibat. Kehati-hatian itu membuat hukum alam yang ditulis menjadi tidak terbantah kebenarannya sekaligus amat baik dalam memunculkan efek keindahan, tidak hanya pada keindahan kata sebagaimana yang telah diungkapkan di atas, melainkan juga pada keindahan suasananya. Bagi orang yang sedang berjalan sendirian di tepi pantai untuk menikmati kesendiriannya, gerimis dan suasana yang kian cepat menjadi gelap seperti peristiwa alam yang memang diharapkan untuk menyempurnakan satu siklus penderitaan.

Parameter berikutnya ialah tentang bagaimana sebuah puisi dianggap mengikuti spirit romantik jika di dalamnya terdapat ungkapan tentang penderitaan yang muncul sebagai akibat mementingkan hasrat sendiri. Penderitaan dalam puisi Senja di Pelabuhan Kecil pertama kali terlihat pada larik pertamabait pertama /Ini kali tidak ada yang mencari cinta/... Siapa lagi di dunia, dalam kehidupan yang umum, yang dapat dikatakan bahagia jika dalam hidupnya dia sudah tidak lagi memerlukan cinta. Siapa lagi yang membiarkan dirinya tidak mencari cinta kalau bukan orang yang tidak lagi membutuhkannya. Kalaupun pernyataan itu tidak dimaksudkan sebagai tidak membutuhkan cinta, orang yang menyatakannya pastilah sedang dilanda kekecewaan dan mencoba meyakinkan dirinya bahwa dia tidak sedang dalam usaha menemukan cintanya. Puisi ininampaknyatidak dimaksudkan untuk mengungkapkan penderitaan karena hasrat orang lain, karena pada keseluruhan bagiannya, terutama di bait awal dan akhir, puisi itu hanya mengungkapkan hasrat si $a k u$.

Parameter berikutnya yang dapat digunakan untuk menguji spirit romantik puisi Senja di Pelabuhan Kecil ialah adanya pengungkapan perasaan dasar manusia. Di bagian awal pada bait pertama larik pertama ada pengungkapan tentang cinta. Apalagi perasaan yang paling dasar pada diri manusia kalau bukan cinta. Meskipun diungkapkan dengan gaya yang menunjukkan seolah si $a k u$ tidaksedang memerlukan cinta, tetapi peristiwa yang disajikannya, memilih berjalan sendiri di pelabuhan yang sepi menjelang malam dan turun gerimis, sangat menandakan bahwa sebenarnya cinta-lah yang dibutuhkannya. Cinta-lah yang sedang dicarinya tetapi karena tidak tahu cara mendapatkannya lalu si sku mengelak dengan menyatakan /Ini kali tidak ada yang mencari cinta/ tetapi di bait terakhir, pada larik kedua, muncul sebuah kejujuran yang menandakan bahwa si aku tidak benar-benar tidak mencari cinta, karena sesungguhnya ia berharap menemukannya. Larik itu berbunyi .../masih pengap harap/....jadi sebagai manusia biasa, bagaimanapun si aku berusaha mengelak, dia tetap 
berharap menemukannya, karena cinta, sebagai bagian dari perasaan dasar manusia, sesungguhnya amat dibutuhkan oleh semua manusia.

Puisi dalam parameter berikutnya baru dapat dianggap memiliki spirit romantik jika mengandung teladan yang adakalanya dibisikkan oleh penderitaan. Dalam puisi Senja di Pelabuhan Kecil, semua peristiwanya dapat diteladani. Hal itu dimulai oleh keputusan yang baik untuk memilih pergi sendiri mengunjungi pantai yang sepi. Orang dengan kegalauan selalu diselimuti rasa marah yang siap meledak, sehingga berada di dekat orang lain akan berpotensi memicu ledakan kemarahan. Oleh karena itu, memutuskan berjalan sendiri, lalu mengunjungi tempat yang sepi, patut diteladani sebagai tindakan yang amat manusiawi. Dalam suasana sepi orang akan lebih berhasil merenung dan membangun kesadaran dirinya sehingga tidak buru-buru menyalahkan orang lain, atau menyalahkan diri sendiri. Sehingga pada puisi ini memang tidak ditemukan bentuk penyalahan diri sendiri atau orang lain. Pendeitaan yang muncul ditelan begitu saja sebagai bagian dari pengalaman hidup sendiri yang diterima sambil berharap akan ada kebahagiaan yang menggantikannya. Bukankah roda tidak selamanya di atas? Yang berarti juga tidak selamanya di bawah. Apa yang bisa menyelamatkan orang dari keputusasaannya adalah harapan. Sehingga sekecil apa pun, selama harapan itu ada, selama itu juga manusia dapat melewati masa-masa sulitnya.

Dengan adanya keteladanan dalam puisi tersebut, tentu saja siapa pun yang akan membacanya akan menjadi pembaca yang tercerahkan. Pembaca yang hanya bisa memahami larik-lariknya secara denotatif memiliki peluang mendapatkan nasihat untuk menghadapi saatsaat yang sulit. Secara filosofis, setiap orang oleh puisi ini diarahkan agar selalu bijaksana menghadapi kesulitannya. Daripada mencari ribut dengan orang lain, yang akhirnya hanya akan menambah masalah dan bukan membantu menyelesaikannya, lebih baik keluar sendiri, hindari orang lain untuk sementara, sampai pikiran menjadi lebih jernih. Bila perlu carilah tempat untuk merenungkan kesulitan itu. Sebaiknya tempatnya juga sepi, jauh dari manusia lain yang mungkin dapat saja dimarahi tanpa alasan. Tidak ada manusia yang tidak mengalami kesulitan, masalah yang menjadi masalah sesungguhnya ialah tidak setiap orang menemukan cara yang tepat untuk menghadapinya. Dan melalui puisi Senja di Pelabuhan Kecil Chairil Anwar menawarkan salah satu solusinya.

\section{JEJAK SHELLEYPADA PUISISAJAK PUTIH}

Percy Bysshe Shelley, ialah salah satu penyair romantis terpenting Inggris dan dianggap sebagai salah satau penyair liris Inggris terbaik. Dia terkenal karena kaitannya dengan John Keats dan Lord Byron. Sheley lahir 4 Agustus 1792, Horsham, Britania Raya, Meninggal: 8 Juli 1822, Lerici, Italia

Tentang spirit romantisme, Shelley mengungkapkan (dalam Golban, 2012) bahwa puisi itu hidup karena dinyatakan dalam kebenaran abadinya, mewakili hukum alam, manusia yang tak dapat dirubah, sebab ada di dalam pikiran sang Pencipta. Puisi itu universal, dan di dalamnya ada suatu hubungan bagi apapun juga yang karena alasan tertentu mempunyai tempat di dalam berbagai kemungkinan variasi kehidupan manusia. Bahasa puisi juga mendapat perhatian penting, baik bahasa, warna, format, religiusitasnya, dan kebiasaan tindakan sipil, merupakan semua instrumen dan material puisi. Di dalam suatu perasaan yang lebih terbatas puisi dinyatakan dalam bentuk pengaturan bahasa, terutama metris, yang 
diciptakan oleh pancaindera. Bahasa arbitrer diproduksi oleh imajinasi, dan mempunyai hubungan ke pemikiran sendiri. Gaya biasa memunculkan lagi keselarasan di dalam bahasa tentang pikiran puitis, bersama-sama dengan hubungannya ke musik, standar produksi, atau suatu sistem tertentu dari format bahasa dan keselarasan tradisional. Walaupun demikian hal itu sama sekali tidak penting bagi seorang penyair.

Shelley (dalam Golban, 2012) menyadari bahwa setiap penyair besar tak bisa diacuhkan perannya dalam menginovasi pendahulunya. Karenanya Shelley, menempatkan imajinasi di dalam pikiran yang bertindak sesuai dengan pemikiran itu agar dapat mewarnainya dengan miliknya, dan menggubahnya, mulai dari unsur-unsur pemikiran lain, prinsip tentang integritas miliknya, dan instrumen moral yang besar yang baik adalah imajinasi. Seperti pendukung romantisme lainnya, Shelley mengutamakan tujuan puisi sebagai teman yang menyenangkan karena semua jiwa dapat jatuh terbuka menerima kebijaksanaan jika penyampaiannya dicampur dengan unsur kesenangannya. Puisi bertindak untuk menghasilkan peningkatan moral orang, membangkitkan dan memperbesar pikiran hingga pada ribuan kombinasi pikiran tidak dapat dipenjarakan. Puisi dapat mengangkat selubung dari kecantikan yang tersembunyi di dunia, dan membuat objek yang umum dikenal seolah-olah mereka tidaklah umum dikenal. Puisi memperkuat organisasi pancaindera yang merupakan bagian badan alami. Di dalam melukiskan puisi, Shelley mempertimbangkan suatu ungkapan imajinasi, sebagai suatu gambaran hidup yang dinyatakan dalam kebenaran abadinya. Puisi menciptakan tindakan menurut hukum alam manusia yang tak dapat dirubah, sebab ada di dalam pikiran pencipta, yang mana merupakan gambaran dari semua pikiran lain. Puisi ialah sebuah cermin yang membuat indah apa yang disimpangkannya.

Dari paparan mengenai pendapat Shelley di atas dapat dibentuk parameter untuk menyatakan sebuah puisi itu romantis atau tidak. Seperti parameter Wordswoth yang ternyata semuanya terpenuhi untuk oleh puisi Senjadi Pelabuhan Kecil sehingga layak mengatakan puisi tersebut sebagai puisi romantis, berikut ini dipaparkan beberapa parameter untuk menguji romantisme puisi Sajak Putihyang ditulis oleh Chairil Anwar untuk tunangannya yang bernama Mirat. Tentang Mirat akan dibahas lebih lanjut setelah paparan mengenai parameter romantisme menurut Shelley.

1. dinyatakan dalam bentuk pengaturan bahasa, terutama metris, yang diciptakan oleh pancaindera

2. Memiliki unsur-unsur pemikiran lain, (prinsip tentang integritasnya, dan instrumen moral yang besar, peningkatan moral);

3. Menjadi sebuah cermin yang membuat indah apa yang disimpangkannya.(S)

4. Dinyatakan dalam kebenaran abadi mewakili hukum alam, manusia yang tak dapat dirubah

5. Mengungkapkan religiusitasnya;

Sajak Putih ditulis oleh Chairil Anwar pada tahun 1944. Yang menarik, sebagaimana yang dapat dilihat nanti pada bentuk lengkapnya, Sajak Putih ditulis buat tunanganku Mirat.Dikisahkan oleh Arham (2014) sosok Mirat memangbenar ada. Chairil dan Mirat tidak benar-benar bertunangan karena orang tua Mirat tidak menyetujui hubungan mereka. Saat datang melamar, Chairil menyusul Sumiratke Paron, Madiun, Jawa Timur. Kenyataan tidak seperti harapan, Chairil diminta mencari pekerjaan dulu. Menurut pengakuan Mirat, ada 
LINGUA, Vol. 12, No. 1, Maret 2015

p ISSN: 1979 9411; e ISSN: 2442 238X; Web: lingua.pusatbahasa.or.id Pusat Kajian Bahasa dan Budaya, Surakarta, Indonesia

Mahyudi, Johan. 2015. Jejak Wordsworth, Coleridge, dan Shelly pada Sejumlah Sajak Chairil Anwar yang Dilengkapi Nama Wanita. Lingua, 12(1): 71 84.

banyak puisi Chairil yang ditujukan kepadanya. Dalam tulisan ini, Sajak Putih dipilih selain karena secara eksplisit menunjukkan nama Mirat, juga karena puisi ini nampaknya yang paling berhasil mengungkapkan romantisme keduanya, bahkan mungkin di luar kemampuan Chairil untuk menyadarinya.

\section{SAJAK PUTIH}

buat tunanganku Mirat

bersandar pada tari warna pelangi kau depanku bertudung sutra senja di hitam matamu kembang mawar dan melati harum rambutmu mengalun bergelut senda

sepi menyanyi, malam dalam mendoa tiba meriak muka air kolam jiwa dan dalam dadaku memerdu lagu menarik menari seluruh aku

hidup dari hidupku, pintu terbuka selama matamu bagiku menengadah selama kau darah mengalir dari luka antara kita Mati datang tidak membelah...

Buat miratku, Ratuku! kubentuk dunia sendiri, dan kuberi jiwa segala yang dikira orang mati di alam ini!

Kucuplah aku terus, kucuplah

Dan semburkanlah tenaga dan hidup dalam tubuhku...

Ditinjau dari parameter pertama, mengenai bentuk pengaturan bahasa, terutama metris, yang diciptakan oleh pancaindera, puisi Sajak Putih menunjukkan potensinya sebagai puisi romantis. Hal itu dapat dilihat pada bait pertama, mulai dari larik pertama/bersandar pada tari warna pelangi/kau depanku bertudung sutra senja/di hitam matamu kembang mawar dan melati/harum rambutmu mengalun bergelut senda/. Pada bait tersebut indra untuk melihat dipadukan dengan indra penciuman, yang kesemuanya diatur sedemikian rupa sehingga menimbulkan irama yang indah. Misalnya /... tari warna pelangi/...depanku bertudung sutra senja/...hitammatamu kembang mawar dan melati/harum rambutmumengalun bergelut/ Amat terlihat bahwa Chairil menggunakan bunyi $\mathbf{m}$ dan variannya sebagai seni menata bunyi yang hanya dimiliki oleh penyair yang inovatif. Larik lainnya yang menunjukkan adanya pengaturan bahasa terkait dengan penggunaan pancaindera antara lain/ sepi menyanyi, malam dalammendoa.../meriak muka...kolam.../dan dalam dadaku memerdu lagu/menarik menari seluruh aku/... 
Parameter berikutnya menurut Shelley untuk menguji romantisme sebuah puisi ialah dengan melihat unsur-unsur pemikiran lain yang ada di dalamnya. Wujud pemikiran lain itu antara lain integritas dan moralitas. Bentuk moralitas yang ditawarkan oleh Chairil Anwar dalam puisi Sajak Putih dapat ditelusuri dengan melihat pendapat Abrams (dalam Day, 1996) yang menjelaskan bahwa untuk memperoleh perasaan romantis, alam semesta direduksi ke dalam suatu tinjauan di mana segalanya, mencakup subjek berupa manusia yang diasingkan dari semua hal yang lain. Jika Abrams menyebutkan tentang manusia yang diasingkan, dalam romantisme, perasaan asing itulah yang jauh lebih penting untuk diperhatikan, sehingga orang yang mengasingkan dirinya pun layak disebut romantis. Pada puisi Sajak Putih pengasingan diri itu dapat kita temukan pada bait terakhir, larik pertama .../Buat miratku, Ratuku! kubentuk dunia sendiri,/... Tujuan alami seseorang mengasingkan dirinya ialah karena peradaban manusia dianggap tidak sanggup menerima model peradaban yang ditawarkannya, sehingga solusi Chairil atas kekecewaan yang dihadapinya karena pinangannya ditolak oleh ayah Mirat ialah dengan kubentuk dunia sendiri. Jika dunia yang dihuni bersama tidak dipahami dengan cara yang sama, apalagi solusi praktisnya kalau bukan menawarkan dunia yang lain, tentu saja, lain dari yang hanya bisa menerima orang bekerja. Dan dunia semacam yang diinginkan oleh Chairil itu kerap menjadi pilihan orang-orang yang hubungannya tidak direstui oleh orang tuanya. Bagi dua orang yang saling mencintai, pendapatan bukanlah pertimbangan karena kesempatan berdua dan senantiasa bersama itu saja sudah merupakan sebuah kemewahan.

Parameter berikutnya ialah sebuah puisi baru dapat dikatakan memiliki spirit romantik jika dapat menjadi cerminan indah dari apa yang disimpangkannya. Untuk lebih memahami keindahan dalam penyimpangan, Day (1996) menjelaskan bahwa prinsip revolusioner dalam romantisme Inggris ditandai dengan adanya tanggapan atas kegagalan idealisme sosial. Sehingga isinya merupakan tanggapan muram atas gejala masyarakatnya yang senang memikirkan dirinya sendiri hingga memunculkan beragam bentuk keputus-asaan. Hilangnya harapan sosial inilah yang semakin jauh menimbulkan perasaan yang lebih gelap. Pada bait terakhir puisi Sajak Putih ada keputusasaan yang mendorong Chairil untuk melakukan tindakan menyimpang. Motivasinya karena ideologi sosial masyarakat pada umumnya menginginkan kehadiran menantu yang sudah mapan, atau minimal bisa menafkahi istri. Wujudnya haruslah menantu yang memiliki pekerjaan tetap.

Karena Chairil tidak memiliki pekerjaan yang menjanjikan kesejahteraan maka secara sosial dia mendapatkan penolakan. Dalam spirit romantik, penyimpangan atas ideologi sosial, disebut juga sebagai romantisme yang berbahaya, karena di era tersebut, pada tahun 1818, muncul tulisan Mary Shelley, roman Frankenstein yang hingga kini masih sangat dikenal, dan telah difilmkan berkali-kali dalam berbagai versi. Dalam versi romannya yang ditulis awalnya tanpa nama sang pengarang yang baru saja berusia 19 tahun, dikisahkan tentang Frankenstein, seorangprofesor gila yang membuat monster dari serpihan dan potongan orang mati. Serpihan dan potongan tubuh itu disatukan dengan cara dijahit lalu dihidupkan lagi dengan menggunakan listrik dari petir.Pengaruh utama roman tersebut, bahkan juga dalam film yang merupakan pengembangan atas ide Shelley, ialah kecemasan akan munculnya kecenderungan anti-sosial. Roman Frankenstein mendorong model romantis-soliter, kreatif-imajinasi, yang secara ekstrim menggambarkan kecenderungan bersifat merusak dan berbahaya. Secara 
eksplisit, puisi sajak putih memuat larik yang mengandung romantisme berbahaya tersebut, yaitu pada bait terakhir, larik pertama sampai keempat/Buat miratku, Ratuku! kubentuk dunia sendiri,/ dan kuberi jiwa segala yang dikira orang mati di/ alam ini!/ Kucuplah aku terus, kucuplah/... Lebih jauh dari keinginan membuat dunia sendiri, Chairil menyebut keinginannya memberi jiwa segala yang dikira orang telah mati. Dalam dunia yang jika berhasil dibentuknya, Chairil memberi isyarat pada kemungkinan untuk melakukan penyimpangan moral dengan meminta ciuman .../Kucuplah aku terus, kucuplah/... sebuah tindakan yang dalam ideologi sosial masyarakat Indonesia yang mayoritas beragama Islam, mengajarkan bahwa ciuman belum boleh dilakukan jika belum menjadi suami-istri. Pada larik .../kucuplah aku terus, kucuplah/... terungkaplah kekuatan romantik Chairil, yang seperti dijelaskan oleh Bloom (dalam Day, 1996) bahwa kecenderungan mengidealkan libido dalam kehidupan seseorang, seperti mengangan-angankan kehidupan yang ideal, dianggap mengerikan bagi kehidupan masyarakat madani, tetapi dalam proses memanusiakan manusia, gaya romantisme bersinggungan dengan bahaya tersebut.

Parameter berikutnya untuk menguji romantisme puisi di atas ialah dengan melihat pernyataan yang mengandung kebenaran abadi mewakili hukum alam, manusia yang tak dapat dirubah. Hukum semacam itu dengan sangat samar terselip pada bait ketiga, yaitu tentang kehidupan. .../selama matamu bagiku menengadah/ selama kau darah mengalir dari luka/ antara kita Mati datang tidak membelah.../Hanya manusia bernyawa yang mampu menengadah. Dan hanya manusia yang masih hidup yang darahnya dapat mengalir deras karena luka goresan. Bait ini tidak dimaksudkan oleh Chairil untuk menyampaikan tentang kematian karena kata Mati ditulis dengan huruf kapital, berbeda dengan kata mati pada bait selanjutnya. Mati pada bait ketiga itu nampaknya ditujukan sebagai gambaran atas perasaan orang tua Mirat yang telah memilih membiarkan dua orang yang saling mencintai terpisah jauh tanpa harapan hanya karena masalah kesejahteraan, yang oleh orang jatuh cinta mana pun, tidak menjadi rujukan pertama.

Parameter Shelley berikutnya untuk mengukur spirit romantik sebuah puisi ialah kandungan ungkapan religiusitasnya. Dari banyak definisi religiusitas, nampaknya yang sesuai dengan spirit romantisme ialah definisi menurut Chatters (dalam Thontowi) yang menjelaskan bahwa religiusitas merupakan sebuah proses untuk mencari sebuah jalan kebenaran yang berhubungan dengan sesuatu yang sakral. Sakral dalam KBBI V1.1 dipadankan maknanya dengan suci dan keramat. Pertanyaan kemudian menjadi lebih mudah diajukan, bagian manakah dalam puisi Sajak Putih Sajak Putih yang merupakan jalan kebenaran, yang dapat dihubungkan dengan sesuatu yang sakral, suci, dan keramat? Bagian ini tidak dapat ditemukan dalam puisi Sajak Putih. Tidak ada petunjuk mengenai proses mencari kebenaran. Untuk mencapai tahapan semacam itu, setidaknya setiap orang harus melewati fase netral, dan dalam Sajak Putih fase itu tidak ada karena Chairil terfokus menawarkan kebenaran dalam versinya sendiri yang bahkan membuatnya rela menjauhi kehidupan masyarakat yang telah memiliki idiologi yang sudah lumrah diterima dan mudah dipahami. 


\section{JEJAK COLERIDGE PADA PUISI CERITA BUAT DIEN TAMAELA}

Samuel Taylor Coleridge adalah seorang penyair, kritikus, dan ahli filsafat berkebangsaan Inggris. Lahir: 21 Oktober 1772 di Ottery St Mary, Britania Raya

Meninggal: 25 Juli 1834, Highgate, Britania Raya. Coleridge menghadirkan peristiwa dan perantaranya, pada sebagiannya dia menyertakan hal-hal yang gaib, orang dan karakter yang terkait dengan hal-hal gaib. Mengenai bahasa puisi, Coleridge menunjuk pada suatu parameter yang mengatur proses peniruan sajak atas kesenangan tertentu dengan memperhatikan keserasian dan jumlah bunyi. Imajinasi dianggap memecahkan, menghamburkan, mengusir, dalam rangka membuat ulang, di mana proses ini mustahil disumbangkan namun bagaimanapun juga diusahakan untuk mengidealkan dan mempersatukannya. Hal itu penting bahkan saat semua objek utama ditetapkan, diperbaiki, dan dimatikan. Di sini Coleridge memunculkan teori tentang imajinasi puitis yang dihadapkan dengan imajinasi utama melalui khayalan. Tujuan puisi, diakui Coleridge, semata-mata demi kesenangan, bukan kebenaran, kompatibel dengan beragam bentuk kepuasan. Dengan demikian puisi adalah komposisi yang dipertentangkan dengan pekerjaan ilmu pengetahuan, dengan menguatamakan kesenangan sebagai sasaran yang segera ingin dipenuhi.Dari penjelasan di atas, dapat disusun sebuah parameter untuk membuktikan sebuah puisi memiliki spirit romantik atau tidak.

1. Menghadirkan peristiwa, perantaranya, orang, dan karakter yang terkait dengan hal-hal gaib;

2. Memperhatikan keserasian dan jumlah bunyi;

3. Dibentuk berdasarkan imajinasi puitis yang dihadapkan dengan imajinasi utama melalui khayalan.

4. Tujuan menulis puisisemata-mata demi kesenangan, bukan kebenaran, kompatibel dengan beragam bentuk kepuasan.

Keempat parameter itu akan digunakan untuk menguji romantisme puisi Cerita Buat Dien Tamaela. Jika pada kedua puisi sebelumnya, nama wanita untuk siapa puisi itu ditulis disertakan oleh Chairil Anwar, setelah judul, untuk Dien, namanya langsung ikut menyatu dalam judul. Tentu bagi pengarang seperti Chairil Anwal, perlakuan istimewa itu bukan suatu kebetulan. Jika tulisan Robert (2014) tentang Dien Tamaila, lebih condong melihat kehadiran wanita itu sebagai sahabat Chairil dalam debat sastra Angkatan Pujangga Baru. Tetapi dalam perlakuan istimewa ini, sepertinya patut dibuka pintu prasangka bahwa hubungan keduanya mungkin tidak untuk urusan intelektual saja. Terlebih lagi karena puisi Cerita Buat Dien Tamaela ternyata ditulis pada tahun yang sama dengan puisi Cintaku Jauh di Pulau. Didasari oleh beberapa kecurigaan itulah maka puisi ini dianggap patut diuji romantismenya dengan menggunakan parameter Coleridge. Berikut ini kutipan lengkap puisinya.

\section{Cerita Buat Dien Tamaela}

Beta Pattirajawane

Yang dijaga datu-datu

Cuma satu 
LINGUA, Vol. 12, No. 1, Maret 2015

p ISSN: 1979 9411; e ISSN: 2442 238X; Web: lingua.pusatbahasa.or.id Pusat Kajian Bahasa dan Budaya, Surakarta, Indonesia

Mahyudi, Johan. 2015. Jejak Wordsworth, Coleridge, dan Shelly pada Sejumlah Sajak Chairil Anwar yang Dilengkapi Nama Wanita. Lingua, 12(1): 71 84.

Beta Pattirajawane

Kikisan laut

Berdarah laut

Beta Pattirajawane

Ketika lahir dibawakan

Datu dayung sampan

Beta Pattirajawane, menjaga hutan pala

Beta api di pantai. Siapa mendekat

Tiga kali menyebut beta punya nama

Dalam sunyi malam ganggang menari

Menurut beta punya tifa,

Pohon pala, badan perawan jadi

Hidup sampai pagi tiba.

Mari menari!

mari beria!

mari berlupa!

Awas jangan bikin beta marah

Beta bikin pala mati, gadis kaku

Beta kirim datu-datu!

Beta ada di malam, ada di siang

Irama ganggang dan api membakar pulau...

Beta Pattirajawane

Yang dijaga datu-datu

Cuma satu

Ditinjau dari parameter pertama puisi di atas jelas menghadirkan peristiwa, perantaranya, orang, dan karakter yang terkait dengan hal-hal gaib. Kegaiban itu amat terlihat pada empat bait pertama yang digunakan oleh Chairil untuk menjelaskan Pattirajawane, yang menurut Roberth (2014) merupakan nama marga orang Maluku. Kegaiban yang pertama ada pada pernyataan si Pattirawane yang dijaga oleh datu-datu. Datu adalah sebutan untuk raja. Apa yang begitu dijaga oleh raja kalau bukan sesuatu yang amat berharga. Rahasia berharganya itu ternyata salah satunya karena jumlahnya satu./Beta Pattirajawane/Yang dijaga datu-datu/Cuma satu/. Pada bait berikutnya ada pengakuan diri bahwa Pattirawane dilahirkan oleh laut, bahkan berdarah laut. Siapa yang begitu dekat dengan bagian dari kehidupan laut Maluku kalau bukan Dien Tamaela?/Beta Pattirajawane/Kikisan laut/Berdarah laut/ kegaiban berikut ada pada kisah mengenai kelahiran Pattirawane yang 
LINGUA, Vol. 12, No. 1, Maret 2015

p ISSN: 1979 9411; e ISSN: 2442 238X; Web: lingua.pusatbahasa.or.id

Pusat Kajian Bahasa dan Budaya, Surakarta, Indonesia

Mahyudi, Johan. 2015. Jejak Wordsworth, Coleridge, dan Shelly pada Sejumlah Sajak Chairil Anwar yang Dilengkapi Nama Wanita. Lingua, 12(1): 71 84.

saat lahir dibawakan dayung sampan, sebagai simbol penggerak ke tengah lautan, penggerak ke tengah kehidupan/Beta Pattirajawane/Ketika lahir dibawakan/Datu dayung sampan/Apa yang dapat dibayangkan jika disebutkan penjaga hutan pala? Pasti sesuatu yang gaib. Tetapi jika dibawa pada realita untuk siapa puisi itu ditulis, sebenarnya Chairil ingin menyampaikan pesan pada salah satu generasimuda asal Maluku yang kebetulan dikenalnya, yaitu Dien Tamaela agar bakat menulis (dayung sampan) yang dimilikinya dapat digunakan untuk menyadarkan masyarakatnya agar tetap menjaga alam warisan nenek moyang/Beta Pattirajawane, menjaga hutan pala/Beta api di pantai. Siapa mendekat/Tiga kali menyebut beta punya namal

Gambaran gaib yang paling nyata ada pada bait ketujuh dan delapan .../Awas jangan bikin beta marah/Beta bikin pala mati, gadis kaku/Beta kirim datu-datu!//Beta ada di malam, ada di siang/Irama ganggang dan api membakar pulau...si Beta (aku) dalam puisi Cerita Buat Dien Tamaela dikisahkan memiliki kekuatan gaib yang mampu membuat pala (tumbuhan yang sangat penting selama ratusan tahun di Maluku) dapat dibuat mati jika Pattirajawane dibuat marah. Bahkan gadis-gadis akan dibuat kaku. Lalu pulau bisa dibakar dengan api. Mungkin Chairil sering dibuat jengkel oleh diskusi-diksusi yang terjadi antara dirinya dan Dien, sehingga dia berkhayal akan memiliki kekuatan yang sanggup membuat gadis menjadi kaku, dia nampaknya ingin sekali membuat Dien menjadi diam, tidak memperpanjang bantahan yang ingin dimenangkan oleh Chairil. Khayalan semacam itu menjadi salah satu parameter Coleridge untuk menguku capaian romantik sebuah puisi.

Parameter terakhir ialah tentang keserasian bunyi. Hal itu dapat dinikmatidari bait pertama larik kedua .../...dijaga datu-datu/Cuma satu// terlihat pengulangan bunyi /tu/. Pada bait kedua juga ada bunyi /ut/ karena adanya perulangan kata laut. Pada bait ketiga larik .../...dibawakan/ Datu dayung sampan/. Pada bait keenam ada reduplikasi kata Mari yang memungkinkan perulangan bunyi /ri/ sampai tiga kali sehingga amat terlihat keserasian bunyi dan jumlahnya.

\section{SIMPULAN}

Pertanyaan utama dalam tulisan ini telah terjawab, Chairil Anwar terbukti memang penyair yang romantis, jika ditinjau dari tiga sajaknya yang menyertakan nama wanita yang secara eksplisit menjelaskan untuk siapa puisi itu ditulis. Setelah diuji dengan menggunakan parameter para pengagas romantisme, ketiga puisi Chairil yang dibahas dalam tulisan ini terbukti merupakan puisi-puisi yang romantis. Ketiga puisi di atas telah diuji sesuai dengan kecenderungannya. Lalu fakta-fakta yang ditemukan nampaknya dapat membantu menjawab beberapa pertanyaan lain yang telah diajukan di muka, antara lain:

1) Tokoh yang paling mempengaruhi Chairil adalah Wordsworth karena semua parameter penyair itu dapat digunakan untuk menguji romantisme puisi Senja di Pelabuhan Kecil. Dengan sendirinya, berdasarkan temuan ini, puisi Senja di Pelabuhan Kecil merupakan bentuk puisi Chairil yang paling ideal untuk membuktikan spirit romantismenya. Juga temuan ini sekaligus menjawab pertanyaan tentang siapa wanita yang paling dicintai oleh Chairil. Jawabannya adalah Sri Ajati. Alasan lain mengapa wanita ini yang paling dicintai juga diperkuat oleh fakta bahwa pada Sri Ajati-lah satu-satunya gadis yang tidak pernah sanggup/berani membuat Chairil Anwar mengungkapkan cintanya secara langsung . 
LINGUA, Vol. 12, No. 1, Maret 2015

p ISSN: 1979 9411; e ISSN: 2442 238X; Web: lingua.pusatbahasa.or.id Pusat Kajian Bahasa dan Budaya, Surakarta, Indonesia

Mahyudi, Johan. 2015. Jejak Wordsworth, Coleridge, dan Shelly pada Sejumlah Sajak Chairil Anwar yang Dilengkapi Nama Wanita. Lingua, 12(1): 71 84.

2) Wanita yang paling disayangi oleh Chairil Anwar ialah Diean Tamaila, selain namanya langsung disertakan menjadi bagian dari judul puisi, juga karena marga Dien begitu diistimekan hingga layak dijaga datu-datu. Perasaan sayang itu, meskipun sempat menguat dan nyaris menjadi cinta, karena telah diekspresikan pada puisi Cintaku Jauh di Pulau, tetapi persahabatan mereka sebagai dua orang yang senantiasa mendiskusikan sastra, telah membuat salah satu kalau bukan keduanya, memutuskan dengan cara masingmasing untuk memilih lebih baik melanggengkan persahabatan dan membiarkan rasa cinta itu membeku dalam kenangan.

3) Puisi Sajak Putih yang dalam banyak lariknya secara jelas menerangkan bentuk kedekatan anatara Chairil dan Mirat yang sangat dekat, dipenuhi oleh larik-larik tentang cinta yang menggelora. Begitu kuatnya hasrat ingin menyatu di antara keduanya membuat Chairil terlalu terfokus menjelaskan bentuk hubungan antara dirinya dan Mirat sehingga melalaikan kesempatan menunjukkan jalan menemukan kebenaran. Dengan begitu, pada puisi ini, Chairil dapat dikatakan gagal memenuhi spirit romantisme karena masih menyisakan satu parameter Shelley.

\section{DAFTAR PUSTAKA}

Arham, Habib.2014. Sepenggal Kisah Cinta Penyair "Chairil Anwar” yang Mengharukan.http://habibarham.blog.com/2012/11/07/sepenggal-kisah-cinta-penyair"chairil-anwar"-yang-mengharukan/ 23/09/2014

\section{Bertemu Putri Tunggal Chairil Anwar.}

http://nasional.kompas.com/read/2013/11/22/1414004/Bertemu.Putri.Tunggal.Chairil. Anwar. 23/09/2014

Day, Aidan. 1996. Romanticism. London: Routledge

Golban, Petru.2012. The Romantic Critical Thinking: Theoretical Incoherence of a Unitary Movement. Mediterranean Journal of Social Sciences, 3(1):127-140.

M. Roberth.2014. Ada yang Ngerti 'Cerita Buat Dien Tamaela' karya Chairil Anwar.https://id.answers.yahoo.com/question/index?qid=20081029055453AARIBaT. Diakses pada 23/09/2014

Puisi Cinta Chairil Anwar, Puisi cinta yang penuh gelora (2)http://www.puisikita.com/ 2008/06/puisi-cinta-chairil-anwar-puisi-cinta_24.html. Diakses pada 23/09/2014

Thontowi, Ahmad. 2014, Hakekat Relegiusitas. http://sumsel.kemenag.go.id/file/dokumen/ hakekatreligiusitas.pdf Diakses pada 23/09/2014

Wikipedia.2014. Frankenstein (novel).http://id.wikipedia.org/wiki/Frankenstein_(novel)23/09/201

Wikipedia.Percy Bysshe

Shelley.https://www.google.co.id/search?q=makalah\%20tentang\%20romantisme\%20c hairil\%20anwar\&gws_rd=ssl\#q=shelley 